Fe de erratas / Erratum

En el artículo

Sergio Arlandis López (2014), "Máscaras de la expresión amorosa en la poesía de Jaime Siles”, Revista de Literatura. LXXVI, 152, pp. 605-619 (doi: 10.3989/revliteratura.2014.02.023)

La afiliación correcta del autor es University of Pennsylvania. Este error ha sido corregido en la versión electrónica del artículo.

Pedimos disculpas a nuestros lectores.

In the article

Sergio Arlandis López (2014), "Máscaras de la expresión amorosa en la poesía de Jaime Siles”, Revista de Literatura. LXXVI, 152, pp. 605-619 (doi: 10.3989/revliteratura.2014.02.023)

The right affiliation of the author is University of Pennsylvania. This spelling mistake has been corrected in the online version of the article.

We apologize for any inconvenience this may cause.

Redacción de Revista de Literatura 


\title{
Máscaras de la expresión amorosa en la poesía de Jaime Siles
}

\section{The Masks of Love in the Poetry of Jaime Siles}

\author{
Sergio Arlandis López \\ University of Virginia-HSP
}

\section{RESUMEN}

La poesía de Jaime Siles no se ha caracterizado, según la crítica especializada, por su intensidad emocional y, ni mucho menos, por el predominio de la temática amorosa. Sin embargo, han estado siempre presentes a lo largo de su obra, desempeñando un papel relevante en esa búsqueda de equilibrio emocional que sí le caracteriza. Así, resulta interesante ver cómo los sentidos se convierten en cauces por los que discurre la experiencia amorosa, la intensa, pero fugaz, fusión de los cuerpos amantes, que pugna por racionalizarse a través de la palabra.

Palabras Clave: poesía amorosa, simbología, visión de mundo, revelación, mundo onírico, tono reflexivo, mito, tópico, flamma amoris, militia amoris.

\begin{abstract}
The poetry of Jaime Siles hasn't been characterized, according to critics, by its emotional intensity, much less by the predominance of the love theme. Nevertheless these have always been present throughout his work, playing a relevant role in the search for emotional balance that characterizes him. Thus, it is interesting to see how these feelings become channels through which run the intense but fleeting emotions of loving beings as they fight to be rationalized through the word.
\end{abstract}

Key words: Love poetry, symbolism, world view, revelation, oneiric world, reflective tone, myth, topic, flamma amoris, militia amoris.

Jaime Siles es un autor cuyo mundo poético, a pesar de toda las variaciones lógicas que puede haber entre sus libros, es significativamente coherente y unitario. Incluso este ha sido un «lugar común» de la crítica consagrada al estudio de su obra: seguir e identificar aquellos aspectos continuos en toda su trayectoria, así como las singulares variaciones que esta mostraba desde la creciente perspectiva de los años. Tales trabajos, guiados también por la opinión del propio Siles, determinaron hasta dos temas predominantes y constantes: la identidad como problema y el lenguaje como realidad (Arlandis, 2011: 15-22). Y si, además, los entrecruzamos (pues los dos van unidos en la voz 
poética que los concreta) encontramos aquello que el mismo poeta apuntara como la gran síntesis temática del conjunto de su obra: «el tema principal de mi escritura es el lenguaje entendido y vivido como una identidad» (Siles, 2007: 32). Visto así, la poética de corte existencial, junto con la metapoesía, parecen no sólo completar este arco evolutivo, sino también complementarse, como si el debate sobre la propia escritura fuera, en su reverso, la diatriba del propio yo poemático y el yo creador, buscando los nexos de continuidad y autonomía existenciales; es decir, las respuestas que la vida nos da no sólo desde la experiencia sensitiva, sino también desde la experiencia gráfica que, a fin de cuentas, es un modo de plasmar la abstracción del pensamiento y del sentimiento vitales.

Este ahondamiento que, sin duda, caracteriza la poesía de Jaime Siles, parece dejar pocos resquicios al tema amoroso. Incluso, se afirma que en la porosidad de sus versos rara vez la pasión o el erotismo, por ejemplo, dejan emanar ese flujo pasional que a veces queda tan ajeno a la reflexión y la meditación. Pero basta detenerse en algunos momentos claves de su trayectoria poética para comprobar que eso, sin ser incierto, sí resulta incompleto para dar plena explicación a los constituyentes temáticos y simbólicos de su obra. Insistimos en esto: señalemos algunos destellos, nunca claves explícitamente argumentadas y vinculadas con estricta cohesión de los componentes. Pero es un claro indicador de su presencia el hecho de que su penúltimo libro publicado hasta la fecha, Desnudos y acuarelas (2009) (o hasta incluso el último de todos, Horas extras, con apenas unos meses en nuestros estantes), esté consagrado, casi en su totalidad, al amor. Y es que, en efecto, parece que no ha sido un tema capital en su obra aunque haya estado muy presente y constante, tal y como tempranamente, en 1986, apuntaba la profesora Irma Emilozzi haciendo un análisis muy sintético (pero esclarecedor) de sus primeros poemarios. Y también, aunque de manera indirecta, lo señalaba García Jambrina al reseñarlo, indicando — de ahí su curiosidad - que se trataba de «una perfecta síntesis superadora de esos ciclos o caminos» (7.3.2009:18).

Dentro de esa continuidad y variación de mundo poético, el tema amoroso, cuando ha sido plenamente identificable, siempre ha servido como auténtico contrapunto emocional en buena parte de sus libros: si la poesía aspira al equilibrio o al desciframiento de una realidad más plena, más elemental, sus poemas amorosos suponen la pérdida de ese control emocional. En su obra, el amor se convierte en el telón de fondo de los cuerpos dentro de esa búsqueda, más o menos segura, de pasión e intensidad desde otros mecanismos de revelación: rescata al ser humano del constante fluir del tiempo o «del espíritu» — como él mismo, refiriéndose a la misma Poesía, señala en su poética a la popular antología de Enrique Martín Pardo en 1970, Nueva poesía española - trasladándolo a la deslimitación de su propio yo, expósito en el campo abierto de los deseos. Y aún siguiendo con tales conclusiones de lectura, podríamos incluso apuntar que, en efecto, una buena prueba del desequi- 
librio que la pasión amorosa provoca se evidencia mediante el uso de un lenguaje bélico y combativo (un aspecto sobre el que, necesariamente, volveremos): pues bajo el tópico del militia amoris se nos representa todo un proceso de invasión poderosa que escapa al control y al régimen del pensamiento. En esta línea, por ejemplo, podemos situar el primer poema de su obra poética completa, «La hora en que los dientes» (Génesis de la luz, 1969), donde la progresiva pasión amorosa se va convirtiendo en un asedio, en una estrategia de puesta en escena de las emociones y de los deseos, de los conscientes y de los inconscientes, de tal modo que las notas musicales (es decir, la belleza sensitiva que también puede producir el poema) «parecen atacarme al corazón / y los arietes van poco a poco derrengando / la Puerta de Ugarit de mi sentido». Y casos similares los podemos cotejar en poemas como «Tragedia de los caballos locos» (Canon, 1973) y en buena parte de un libro como Semáforos, semáforos (1990): «Mayo del 68», «Frisos de los arqueros», por ejemplo. Así, lo realmente cristalino en estos poemas es la estrategia (el lenguaje, la forma, el ritmo) y aquello que resulta más impredecible y convulsionador es la pasión que exige una expresión que reitere las emociones producidas, como el eco con la voz: este es, sin duda, uno de los motivos principales por los que temática amorosa y lenguaje bélico se asocian, ya que sus consecuencias son gozosamente impredecibles y devastadoras o, mejor aún, apelan a la aniquilación de una parte del yo para reconstruir(se) una identidad, reafirmada esta vez, no en la palabra, sino en la materialidad. La palabra es, también así, como el eco de lo vivido.

Toda muerte y nacimiento simbólicos que implica el amor nos conecta con aquel tema de la identidad como problema, aunque dudamos que, visto así, nos enlace con aquel y el lenguaje como realidad. Pero no es así: la poesía amorosa en Siles se inserta en un debate metapoético, como ocurriera también con Gustavo Adolfo Bécquer y su teoría de qué es la poesía, quién la provoca y quién la transcribe usando qué técnicas para conseguir que aquellas «palabras sin sentido; / cadencia que no tienen / ni ritmo ni compás» (Rima III) acabasen convertidas en una inteligente mano «que en un collar de perlas / consigue las indóciles / palabras reunir». Tras la estrategia del intelecto quedaba el mundo de las pasiones donde la mujer, en cuanto forma concretada en la escritura (tinta y mujer van unidos habitualmente en la poesía silesiana) se acaba convirtiendo en una respuesta metapoética de fondo, como también lo expresaba el propio Bécquer: «¿Qué es poesía? ¿Y tú me lo preguntas? / Poesía...eres tú». Una curiosa conexión que no ha sido estudiada hasta la fecha en la poesía de Jaime Siles. Pero vayamos desentrañando en qué consisten estos puntos de relación que nos sirvan para determinar que, en efecto, su poesía amorosa es mucho más predominante que sólo aquellos casos contrapuntísticos señalados; pero, sobre todo, que identidad y lenguaje también se forjan en ellos para enriquecer ese debate metapoético que sí resulta identificativo de su trayectoria. 
La continuidad de todo un mundo poético cabe buscarla, entre otras cosas, en la evolución de sus formantes simbólicos que, en cierto modo, no sólo se reiteran sino que, además, se renuevan en su formulación y, sobre todo, complementan aquellas constantes temáticas que encontramos en un autor. Una manera de llevarlo a análisis es, por ejemplo, seguir los símbolos de protagonización, sin olvidarnos que, como señaló Carlos Bousoño en la Teoría de la expresión poética $\left(1999^{1}\right)$, y ratificó para sí mismo el propio Siles, «la persona que habla en el poema, aunque con frecuencia mayor o menor (no entramos en el asunto) coincida de algún modo con el yo empírico del poeta es, pues, sustantivamente, un personaje, una composición que la fantasía logra a través de los datos de la experiencia» (Bousoño, 1999: 32). La persistencia simbólica de dicho personaje lo convierte en rasgo de continuidad del mismo modo que, en su representación, también lo anuncia como obsesión, fantasma o espectro (enigmático y alumbrador al mismo tiempo) que identifica a ese sujeto lírico.

Fue Charles Mauron quien, en primer término, definió el mito personal como el fantasma dominante que se revelaba en la superposición de las obras de un escritor (1962: 91): forjado por la recurrencia principalmente, lo define más tarde como un espectro simbólico que recorre los textos de un autor, abriendo la posibilidad de variaciones concretas, pero siendo recurrente en los aspectos básicos (cabe resaltarlo) que lo forman. Mauron lo identifica, debido a la rama de conocimientos a la que pertenece, como la expresión de la personalidad inconsciente a través del cual, el yo creador y el social se unen o, como él mismo puntualiza, se superponen. Pero el hecho de que en un autor podamos identificar una imagen actoral más o menos recurrente o predominante, el llamado mito personal, no significa que no use otras máscaras líricas, pues esta misma combinación de personajes será un elemento determinante para la construcción más completa de su mito personal ya no sólo como máscara literaria, sino también como rasgo definidor de una actitud vital: «la destacada constancia de redes asociativas y de figuras sugiere, por otra parte, que los conflictos deben ser, ellos también, permanentes, interiores en la personalidad del escritor» (1963: 194-195).

Frente a esto, debemos tener muy presente que uno de los rasgos identificadores más significativos del yo poemático silesiano es la voz, pues de ella emerge una imagen del silencio que, sin embargo, tiene como primer objetivo el testimonio de la expresión viva, es decir: la abstracción de su forma irá progresivamente ajustándose a ciertos patrones simbólicos más acordes con aquello que hace y escribe, que con su identificación física concreta. Es, por tanto, un punto concéntrico que convoca para sí la experiencia y su materialización lingüística. Pero, además de este movimiento centrípeto, también te-

\footnotetext{
${ }^{1}$ Nos referimos a la sexta edición.
} 
nemos que, dentro de los constituyentes simbólicos de ese yo poemático, este se muestra predominantemente en movimiento (Castro, 2009: 162 y ss.). Es el tópico del homo viator, como ya señalamos en la introducción a Cenotafio. Antología poética (1969-2009) (Cátedra, 2011), dividido en dos momentos: por un lado, la poesía escrita hasta Semáforos, semáforos, marcada por la voluntad de desplazarse, de coronar los objetivos de la vida, de la obra y de la vida como obra; por otro lado, y tras el citado libro, el movimiento inverso en el que afloran la caída y el deseo de quietud. A estos principios articuladores esbozados aquí, cabe añadirle que ese yo poemático es creador y, al mismo tiempo, creación: desde el pulimento de la forma, desde la perfecta sincronización del lenguaje, en lo melódico, en lo conceptual y en lo gramatical, podríamos unir identidad y lenguaje en el marco de la realidad poética como dos cuerpos que se estorban pero se necesitan a un mismo tiempo. Por tanto, una última cualidad a destacar de esa máscara actoral silesiana es la de erigirse como orfebre o forjador de la materia poética, por muy evanescente, flamígea o fluida que esta sea: el herrero y/o escultor que, contra el yunque o mármol de la página, quiere mostrar cómo se esculpe su propia identidad y la experiencia que la complete. Este complejo juego de planos en el que el yo poemático y el poeta se distancian hasta tal extremo que se unen en un punto equidistante de la lejanía, nos confirma toda su etapa metapoética, donde el yo indaga las formas, no sólo en su resultado final, sino también - y en muchos casos - sobre la posibilidad de delimitar su materialidad (véanse, por ejemplo, las características aliteraciones en su poesía). El propio Siles, en su poética titulada «El yo es un producto del lenguaje» publicada 2007, señalaba: «Poetizar es un acto de Realidad y de lenguaje, transformar los nombres hasta el substrato primigenio [...] devolver la realidad a la Realidad», para seguir apuntando que los poemas son

creaciones de una percepción, epifanías de una identidad que sólo toma cuerpo en la discusión y que sólo vive en el lenguaje o, al menos, sólo nace de él. Eso - y no otro cosa - es la experiencia poética: conocimiento de la tradición y asunción de la persona poemática, aceptación de los riesgos del habla y distinción diáfana entre lenguaje y realidad (Siles, 2007: 29).

Por tanto, transformación, revelación y movimiento, son rasgos identificativos del mito personal silesiano, más allá de un rostro u otro. Ahora bien, en su poesía amorosa todos estos aspectos adquieren una figuración muy concreta y recurrente: la figura mitológica de Pigmalión, complementada, en algunos casos, con la de Hefesto.

Jean Chevalier y Alain Gheerbrant, en su Diccionario de símbolos, definían al forjador o herrero (en cuanto a forma simbólica representativa del orfebre), justamente en estos términos: «De los oficios relativos a la transformación de los metales, el de herrero es el más significativo en cuanto a la importancia y a la ambivalencia de los símbolos que implica. La forja entraña un aspecto cos- 
mogónico y creador, un aspecto asúrico e infernal, y por fin un aspecto iniciático» (1999²: 560). Y es ese mismo proceso transformador el que se da en la poesía amorosa de Siles siguiendo el señalado esquema pigmaliano.

Ya José Olivio Jiménez (1976) había visto en el temprano Canon (1973) la base modernista del mismo, dejando en un horizonte lector el mito de Leda (y la pasión amorosa y seductora de Zeus), es decir, la transformación estética de los cuerpos (el cisne-signa), tal y como lo interpretaron los griegos, de dos formas en una perfecta y armónica simbiosis. Incluso como el propio Chevalier apunta sobre este símbolo,

El cisne es femenino en la contemplación de las aguas luminosas, es masculino en la acción. Para lo inconsciente, la acción es un acto [...] La imagen del cisne, por consiguiente, se sintetiza, para Bachelard, como la del Deseo, llamando a confundirse las dos polaridades del mundo manifestadas por sus luminarias. El canto del cisne, por consiguiente, puede interpretarse como los elocuentes juramentos del amante (Chevalier y Gheerbrant, 1999: 307).

Esta transformación surgida de la combinación de dos extremos (esa es, pues, la idea que apuntamos), junto con la figuración del orfebre, nos lleva, curiosamente, a que el libro, desde otros dictados, fuera definido no sólo por su intelectualismo, sino también porque en él el deseo insonoro pugna por hacerse palabra constante ante la inconstancia humana. La unión con una creación femenina, a la que se le busca dotar de cuerpo autónomo, pero al mismo tiempo que sea fiel al deseo de su creador, con la capacidad de manejar la forma del lenguaje como materia prima desde la experiencia del deseo, no es más que una representación, muy elemental, del mito de Pigmalión: siempre con el propio deseo como denominador común, cabe preguntarse si en la poesía de Siles no existe esa primera aspiración a la materialización (aunque vaya cambiando de formas), y de ahí, a la concreción, a la autonomía, y, finalmente, a la fusión o consumación con el deseo cumplido: el éxtasis final. Claro, recordemos que Pigmalión fue aquel rey chipriota que buscó incansable, desde un ideal propio de belleza (el de Afrodita), a su amada imposible en su realización exacta. Esta actitud inconformista - masculina en la acción, como decía Chevalier - lleva a pensar que el paradigma de la mujer que forjamos para nosotros mismos, existe, pero es fugaz y, aunque tenemos la esperanza de hallarla, siempre nos queda esa incertidumbre del posible fracaso. Un ejemplo lo tenemos, precisamente, en Canon, en el poema «Cuerpo enamorado», que es el primero del poemario y va precedido de una cita de Ovidio quien, en su Metamorfosis, explicaba, precisamente la historia de Pigmalión y su marmórea amada ${ }^{3}$. Curiosa coincidencia que nos invita a imaginar ciertas correspondencias con lo aquí tratado.

\footnotetext{
${ }^{2}$ Hacemos referencia a la sexta edición

${ }^{3}$ Aunque Ovidio no dotó de nombre a la escultura, se le viene llamando Galatea, aunque ignoramos el origen de tal nombre y el momento exacto de su nombramiento. Tanto en
} 
Recordemos también que el propio Pigmalion, desanimado por no encontrar a una mujer próxima a su deseo real, decide apartarse (es decir, reflexionar) del mundo y moldear esculturas que trataran de concretar la imagen de ese ideal abstracto perseguido: el recogimiento creador. Escultor y herrero aquí se unen en lo elemental, como ocurre, precisamente, en el poema «Cuerpo enamorado» pues, se nos apunta:

\footnotetext{
Cuerpo que tuvo origen, eterno, entre las llamas.

Fue de la luz y rodeó la sombra.

Labios de mar quemados por los astros,

un día muertos.

¡Cuántos pájaros ciegos,

de ojos rotos, caídos por la acera!

Abrir las manos y entornar los párpados.

¡Qué lujuria de besos nunca dados!

Queda la madrugada, náufrago de la sombra.

Tu pensamiento y tú, sois de la muerte.
}

Resulta clarificador en cuanto que, por un lado, nos anuncia la transformación y, por otro, la imagen del amor bajo el tópico del flamma amoris. Pero una vez forjada la forma, y la búsqueda de una belleza, clara y luminosa que sí tiene («fue de la luz»), nos encontramos un deseo, rodeado de sombra (bien la opacidad de los cuerpos o de la materia, o bien el ámbito que habitualmente rodea al sueño o deseo); y posteriormente, la insatisfacción con un acto amoroso que no se completa nunca más allá del pensamiento, en ese intento de reconstrucción de la memoria; hasta que, al final, ese movimiento de fusión se ha transformado en dura reducción, no en plenitud: «Tu pensamiento y tú, sois de la muerte». Y es que en estos versos el objeto de deseo está demasiado subjetivado aún: la experiencia personal impera todavía como horma de esa belleza absoluta que se persigue, así que el amante-orfebre-escultor no ha buscado en la esencia en sí de la experiencia, sino en lo más externo de ella, en los labios concretos y en su rememoración cayendo en la cuenta de que, para poetizar ese acto y para conseguir la anhelada belleza objetiva que dé claridad emocional a lo vivido, debe buscar otros materiales que, en verdad, le conduzcan al hallazgo revelador y cognitivo que garantice la plenitud del creador.

El salto, por tanto, (si un libro como Alegoría nos lo permite teniendo en cuenta que no hay temática amorosa en él), es hacia la esencialización. Seguido a Canon encontramos Música de agua que, para Andrew Debicki

el libro de Robert Graves, Los mitos griegos (2005), como en el Diccionario de mitología clásica (2001) de Constantino Falcón, Emilio Fernández y Raquel López, se usa el nombre de Galatea. Por supuesto, la lista de libros que parten de tal nombre es tan extensa que tan solo cabe eco de su existencia. 
significó «la reducción de la realidad a elementos cada vez más esenciales, culminando en el signo y en el silencio» (1997: 229). Si bien, en este poemario, tras haber encontrado la horma del lenguaje que ha definido una emoción (una intuición puramente sensorial) la escritura se debatirá en torno a su materialización gráfica, donde el espacio en blanco adquirirá significado pero, sobre todo, se convertirá en metáfora de ese silencio, como anunciaba Debicki, que es tanto como decir que trata de representar el origen de la palabra poética. Pensemos, en todo caso, que Pigmalión, tras la búsqueda y definición de su concepto absoluto de belleza ${ }^{4}$, descubre, entre sus moldes (la técnica se perfecciona), a Galatea ${ }^{5}$, de la que se queda prendidamente enamorado: Pigmalión, una noche (curioso que este mismo libro tuviera como un primer título Lectura de la noche), sueña que ésta cobra vida y logra unirse amorosamente con ella. Fijémonos que en el poema anterior, se tiende a la reducción en el uno (no a la fusión); en cambio, en Música de agua vemos cómo en la restructuración de la propia experiencia, se destruye o secciona un tipo de imagen para alzar otra, y este es el auténtico hallazgo revelador que muestra un posible rostro del deseo al que, por lógica, se le intentará dar forma o materialidad desde la propia escritura. Clave, en este sentido, es el poema «Metamorfosis», cuyo título ya resulta suficientemente explícito:

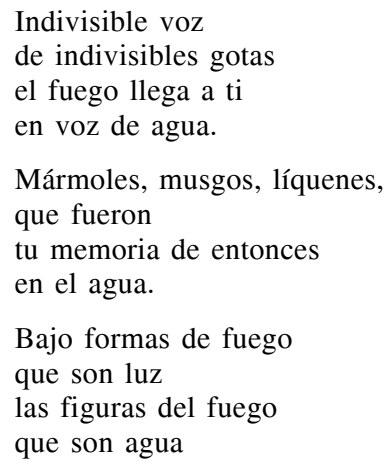

El líquido y el fuego, en el mundo del herrero, son estados que se transforman bajo su mano y su técnica, del mismo modo que en la poesía de $\mathrm{Si}$ les la tinta se convierte en forma de expresión emocional, en voz poética. Curiosamente en esa mutación de las formas, el fuego, como en el poema de Canon, llega desde un origen que se desconoce. Pero lo significativo es que

\footnotetext{
${ }^{4}$ Pongamos el caso de que un libro tan cosmogónico como Alegoría podría servirnos para expresar la gestación de todo este proceso iniciático, o lo que Joseph Campbell llamaría «el vientre de la ballena» (1999: 88-93).

${ }^{5}$ Insistimos en la eventualidad y circunstancialidad de dicho nombre
} 
el mármol (que remite al material pigmariano) también hace acto de presencia en este poema que, a simple vista, no definiríamos como amoroso ${ }^{6}$.

Llevados, pues, por el sueño de Pigmalión, nos adentramos en la figuración de esa belleza tan plena como objetivada, que pretende definirse e ir adquiriendo, poco a poco, un rostro, un nombre, una forma cada vez más concreta y fiel al deseo de su creador. Así, el amante silesiano busca seducir con el lenguaje: es la musicalidad que le conduce a la fusión con lo creado, entrando en el juego de las posibilidades, como demuestra el poema «Enigma» donde «Una falda, una dama y unos pies / en la tarde demoran los encajes». Aparece el erotismo, no como descubrimiento del cuerpo, sino como expresión de la emoción reconducida hacia los sentidos: no olvidemos que Música de agua juega, para seguir con la terminología ya empleada, con los sentidos de la vista (a través de la grafía y del espacio en blanco) y del oído, en la materialización del lenguaje, es decir, en el intento de dotar de realidad a ese lenguaje que no sólo busca expresar, sino también hacerse expresión ${ }^{7}$. En esa dualidad de intenciones la mujer se convierte en el enigma de la noche, que no se adentra en ella, sino que de ella emerge, cambiando, pues, la dinámica anterior: fijémonos, en todo caso, que en aquel poema de Canon, tras la presencia o ausencia de amor, los cuerpos etéreos en la memoria se reducen a uno y, de ahí, hacia la muerte (como también sugiere el célebre poema «Tragedia de los caballos locos» del mismo libro); pero en el poema «Miniatura» de Música de agua, el ritmo «abre la noche de tu mano en dos». Tiene que ocurrir, pues, que el deseo adquiera la autonomía suficiente como para poder verlo desde la distancia y conseguir, en consecuencia, no la reducción, sino la fusión. Por tanto, este proceso de ruptura o desmembramiento se ha producido y la imagen ideal de mujer se ha formado o se está formando con mayor claridad: su reconstrucción intelectual—la idea esencial—busca ahora

\footnotetext{
${ }^{6}$ Sólo con la finalidad de trazar y evidenciar la pasmosa correspondencia interna de su obra, en su libro Desnudos y acuarelas, observamos que esta misma imagen se repite para definir a la amada, aunque, claro está, con las variaciones lógicas que hay entre libros, mostrando, como dijimos, la perfecta coherencia simbólica de toda su obra:
}

La música del agua
dorada de la orilla
recorría en piragua
una ola amarilla
que sus pies rodeaba
formando una sanguina
entre brillos de lava
de verdor turmalina

${ }^{7}$ Para profundizar en este aspecto tan amplio de la imagen de Pigmalión, véase el estudio de Ana Rueda (1999: 83-86). De igual modo, resultará útil consultar el amplio volumen coordinador por Facundo Tomás e Isabel Justo (2005). 
lo sensitivo que reafirme la auténtica existencia de un deseo. Advirtamos, en todo caso, que estos tres primeros libros del autor no son, sin embargo, pródigos en el testimonio amoroso.

Entonces alcanzamos un libro como Columnae que, curiosamente, está dedicado a Ela, mujer que acompaña al poeta en la noche, que congrega amor y compañía. Consecuentemente, existe ya la concreción y la concentración del deseo. Es la escultura que adquiere un nombre propio, su identidad: un rostro para su particular Galatea. Pero ocurre que en el espejo del libro la realidad no es tampoco la misma, así que Pigmalión entra en su propio conflicto: ¿reafirmar lo real y dudar del lenguaje o dudar de la realidad y reafirmar el lenguaje? Columnae es un libro, como el propio Siles indica, de «afirmación vital», una aceptación del amante-orfebre que busca asentar sus estrategias de seducción, de ahí que prime, sobre todo, la reflexión sobre el propio proceso de creación: busca conciliar esa dos mitades que han emergido del acto creador, armonizarlas para lograr la complementariedad entre el deseo y la realidad, entre el yo y lo ajeno. Y resulta llamativo saber que esta reafirmación del Siles hombre-poeta coincide con el fracaso de Pigmalión poético quien, tras la nocturna noche de pasión amorosa, no encuentra a Afrodita para que se compadezca de él y le dé vida a su creación, como sí ocurre en el relato mitológico. En cambio, busca dársela él mismo a través de la sonoridad del lenguaje. Y decimos fracaso porque todo deseo tiene o implica su trauma o su vacío; así, consigue la forma pero acaba clamando por el cuerpo, por la experiencia que, en su filtración sensitiva, confirme que existimos: de ahí que en algunos poemas amorosos, a partir de este momento, se combinen gozo y dolor, pues son dos formas de sentir la vida en nosotros mismos. Por ejemplo, en el poema «Textualidad en comas», que sugiere un claro juego de palabras con el término «cama», el amante pigmaliano se adelanta en el proceso de seducción y afirma

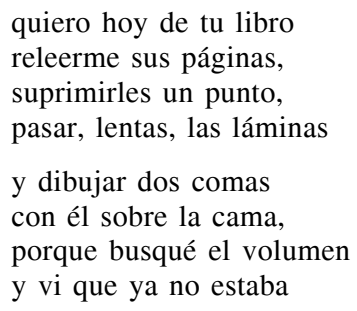

En efecto, se trata de Pigmalión soñando la posible materialidad de su deseo: ascendentemente el poema va del sonido («gota en el agua»), a la letra, de ahí, a la palabra que convoca los significados («Sólo el cuerpo conoce / la verdad que nos salva»), hasta una «Página de la carne»y, finalmente, al cuerpo del libro que lo sintetiza todo. Es el proceso creador que busca corporeizarse, aunque el final sea, de nuevo, el difumino de la sombra ¿alguna 
vez se ha señalado este poema como amoroso? No, nunca, porque es la ingeniería del poeta la que está destellando con más fuerza, pero en verdad es un acto amoroso implícito que no logra completarse plenamente. El lenguaje, pues, es imprescindible instrumento de creación y cognición, y, al mismo tiempo, límite o quimera de los sentidos. Lo expresa igualmente en el poema «Marina», donde «Una antorcha es el mar y, derramada / por tu boca, una voz de sustantivos, / de finales, fugaces, fugitivos / fuegos fundidos en tu piel fundada», para acabar con el terceto «Tu cuerpo suena a mar. Y tu figura, / en la arena del aire reflejada, / a sol, a sal, a ser, a son, a suma». De nuevo el fuego fundido como la materia de la que surge la amada y que - de nuevo se asocia a Pigmalión con Hefesto o Vulcano (y Pandora) - devuelve una forma, una categoría, del lenguaje: pero si la amada es fugaz, si el instante de pasión es pretendido y buscado sin reparos, es por su carácter efímero y el éxtasis que esa fugacidad provoca. La grafía aspira a fijarla diafanidad del tiempo interior, pero la musicalidad del lenguaje es lo único que la refleja con exactitud, por lo que retener la melodía es retenerla a ella, en su simétrica réplica (como apunta el último verso leído). Y esa es la clave: retenerla, conseguir que Galatea no se diluya al acabar el sueño o la clarividente experiencia de la noche. Lo vemos, igualmente, en el poema «Nadadora vestida», donde encontramos que, junto a ella, hay «tonos y timbres, tintas, tactos, textos», para que en los versos finales se nos apunte: «Y tu cuerpo y el mar son una misma / sucesión de sonido y de deseo». Indiscutiblemente, se unen estos dos conductos de su poesía pero ¿quién retiene al deseo? En el poema inmediatamente posterior, titulado «Mujer sintagma», el cuerpo de la amada, como forma de retención, pasa por las cuadraturas de la gramática, quizá para concretar su moldeado y su función, de ahí que acabe con «un sistema de signos que es acaso / el conjunto de rasgos que son Ella».

El grado de objetivación de la imagen ideal de amada ha adquirido tal estado de autonomía con respecto a su creador que tiene su propia identidad, su propia verdad y realidad: el amante-orfebre siente el gozo del creador que ve cumplida la expectativa de su obra, pero también la insatisfacción de acabar el proceso demiurgo, tan excitante, tal y como Siles apuntó en una entrevista en 1986 tratando precisamente sobre la publicación de este libro: «El lector conoce el resultado, pero el poeta vive el proceso. Y como en la ciencia, la aventura más feliz es la del proceso» (Basualdo, 1986: 35). El poeta, por tanto, escribe desde el deseo de unión: aquello que nació de la imaginación y con la que busca reencontrarse, cumpliéndose, realmente, la teoría aristotélica del neuma, expuesta en su libro De anima: el movimiento o pasión producido por la sensación se transmite a la fantasía que puede generar el fantasma (o sea, la imagen) incluso en ausencia del objeto percibido. Ahora bien, si las imágenes, para Aristóteles, son como sensaciones pero sin materia, en la poesía de Siles esas imágenes, en cambio, generan su materia fónica dando una mayor sensación de realidad, pero nunca llegando a suplantarla 
o sobreponerse a ella: dentro de los límites de la página (de la noche, del sueño, del éxtasis revelador) se cumple la unión, como en Pigmalión, visible en el poema «Kairós» que tanto recuerda, en general, aquellos primeros versos de Bécquer que enunciamos al comienzo de este trabajo:

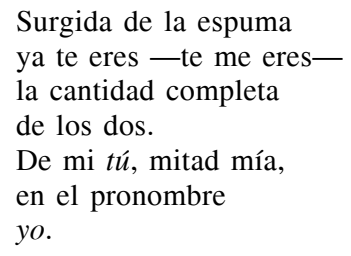

Esta fusión poético-amorosa acaba con el desvelamiento de una condición que en el poemario siguiente desarrollará en versos como

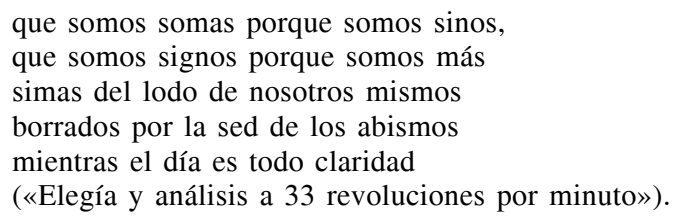

Y hasta llegar a este punto, previamente ha revelado (ya otra vez en Columnae) que «de qué negado sí sus baldaquines / si el deseo se cumple en el deseo» (poema «En el deseo»). Certificación de la noche que reafirma al yo como realidad compleja y sus fantasmas: lugar para el simulacro de la fusión total.

Pigmalión, por tanto, acepta la quimera de su deseo o, mejor aún, los límites reales de su ilimitada imaginación, así que, de nuevo, surge el concepto de «retener» el instante, pues, como dijera Siles ya en 1970, la poesía no es más que el reflejo y la salvación de la realidad. En consecuencia, Semáforos, semáforos y su sintomática primera parte titulada «Madrigales urbanos», va a ahondar en este nuevo reto del amante-orfebre: testigo de la efímera esencia humana, rodeado el ser humano de instrumentos inútiles por disfrazar la realidad que nos cerca (luces de neón, locales que se prolongan en el día, etc.), el amante pretende fijar la figura del amada, saliendo en su búsqueda (otra vez, pues, el movimiento también pigmaliano). Precisa de la emoción exterior, del impulso que le empuje a sentir, de nuevo, la invasión sensitiva del deseo. Forjar, en definitiva, otra vez su Galatea desde la experiencia concreta, desde la más cotidiana vivencia y no desde el ideal, llamémosle cultural, de lo que sería su rostro: ni la noche, ni el éxtasis creador. El amante busca en su agenda más cotidiana el momento de plenitud sensitiva, como ocurre en el poema «Comisión de servicios»:

Si lo dijera todo, toma el tren.

Y, si no dice nada, una primera.

$\mathrm{Y}$, si te dice algo, una litera. 


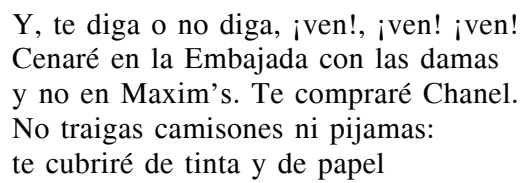

Semáforos, semáforos es, por tanto, clave en esa nueva aventura iniciática del yo poemático silesiano, que busca en el mundo exterior la expresión de su deseo, y para justificar tal consideración basten los ejemplos de poemas como el propio «Semáforos, semáforos» donde, tras ver a una chica en la acera, el amante la identifica con su ideal, aunque el tiempo lo empuje hacia un destino del que es, en cierto modo, dependiente. En el regreso que, en verdad, todo poema significa, ella acaba convirtiéndose en sombra, en humo: «el aire me grafía / aún su silueta». Nuevamente el fantasma de la amada. Otros ejemplos que siguen esa misma dirección son «El humo del cigarro difumina los dedos», «Epilion», «Desciframiento», etc. y se concreta en dos principios articuladores: por un lado, la doble transformación de la realidad y el lenguaje (o a la inversa), visto, perfectamente, en el poema «Acis y Galatea»; y, por otro, la definición de un léxico bélico, como ya dijimos, para describir la pulsión invasora o furor amoris de la pasión amorosa que no es más que una búsqueda de su propia Galatea en otros rostros reflejada.

Así, salvando la llamativa coincidencia que existe en el nombre de la protagonista, en el poema «Acis y Galatea» encontramos versos como:

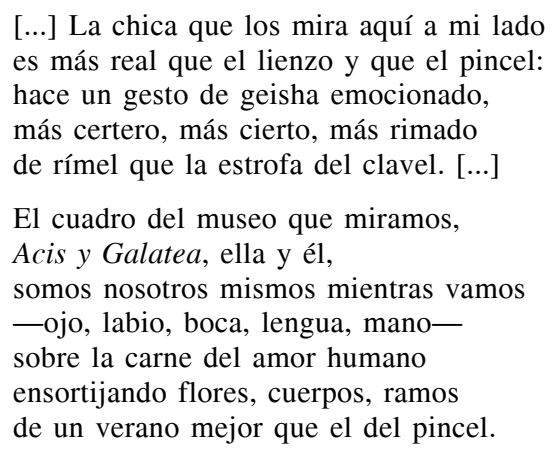

Con lo cual, tenemos que se pretende que, de una vez, esa imagen universalizada a través del arte (véase, escritura) se personalice y se concrete para que la vida, así, se abra paso a través de la quietud de la obra. El movimiento, la fusión de esos contrarios que apuntábamos con el mito de Leda, se anhela y se provoca, pues sólo la forma ya no satisface: la poesía de Jaime Siles se orientará, a partir de este libro, hacia la vivencia, y no sólo hacia la reflexión propiamente. La necesidad de los cuerpos convierte a la poesía en umbral de un deseo subversivo que busca salir de su cárcel inmaterial. Y ¿cómo se expresa ese mismo deseo? A través de la invasión del instinto, 
mediante la creciente pérdida de la armonía que implanta el pensamiento: poemas como «Friso de los arqueros», por ejemplo, lo expresa claramente: «Las gafas, sí, las gafas / de destellos certeros / hicieron disparar / a todos sus arqueros». Y es que el orfebre-herrero (no tanto como el orfebre-escultor que está asociado al agua) está directamente relacionada con el fuego y, por tanto, con Marte, dios de la guerra en la cultura romana.

La poesía amorosa de Jaime Siles, para ir concluyendo este pequeño esbozo de lo que, sin duda, debe ser tratado con mayor profundidad aunque aquí, al menos, hemos intentado señalarlo como un dato a tener en cuenta en su estudio, es la combinación (no olvidemos que la señalamos como el contrapunto emocional de su poesía) de dos extremos muy delimitados simbólicamente: el agua y el fuego, como contrarias y complementarias formas que condensan, por un lado, la reflexión del agua (honda, profunda, clarificadora pero al mismo tiempo enigmática y constante) y la pulsión del fuego (rotundo, feroz, inclinado hacia lo efímero tanto como a lo gratificante instantáneo). Sin duda, Agua y fuego ocupan un lugar determinante en el mundo poético silesiano por su valor ritual, su naturaleza elemental, la pureza que de ellos emana e, incluso, su doble poder, vivificador y destructor al mismo tiempo. El primero de ellos permite ahondar en las formas, sumergirse en lo real y en lo onírico, volver al origen de la existencia. El segundo, estudiado certeramente por Morcillo (2002: 112-116), no se adentra en la reflexión, sino en la intensidad de la acción: es la llama que pretende permanecer en su instante fulgúreo, aun a pesar de conocer que su ineludible final es la ceniza. Porque el fuego se muestra tan revelador como destructor, de ahí que el amor recurra al lenguaje bélico. Este elemento, de raigambre petrarquista en lo amoroso, se convierte en una expresión de satisfacción inmediata desde una perspectiva contemporánea: no purifica, pero eleva al ser humano a la plenitud de lo físico y su materia, al permitir que el instinto libremente se manifieste. Pero Siles no sólo aspira a realizar ese deseo de lo sensorial, también pretende elevarlo a su máxima condición de belleza, es decir, a convertirlo en cauce de conocimiento y de sensibilidad al darle un volumen escultural: hacerlo arte y convertirlo en modulación perfecta de las formas y de los cuerpos, asociando este fuego con el agua o el espejo. Son las dos expresiones de Pigmalión y de Hefesto con el fondo soterrado del relato entre Leda y Zeus: máscaras que, de un modo muy particular, se expresan a lo largo de su obra, a veces de manera más nítida y otras, en cambio, no tanto (piénsese que aquí no nos hemos adentrado en toda su producción posterior a Semáforos, semáforos, donde, curiosamente, vienen a confirmarse todos estos aspectos de representación actoral). Lo que sí resulta significativo es poder apreciar que, detrás de la aparente rigidez emocional de sus versos, duerme el más ardiente sueño de todo amante: ver convertido su deseo en un cuerpo al que asirse en permanente furor pasional, en comunión constante pues los dos son lo uno y lo distinto, en elevación de los sentidos hasta la más alta cota de fusión con 
todo lo creado. Es decir, tras la rectitud de las formas cristalinas, el volumen de los cuerpos en pleno acto amoroso, en un estallido de vitalismo que anuncia al amor como el único rescate posible de la rueda feroz del tiempo: misión que, sin embargo, también espera Siles de la propia poesía.

\section{BIBLIOGRAFÍA CITADA}

Arlandis, Sergio (2011). «Introducción», Cenotafio. Antología poética (1969-2009) de Jaime Siles. Madrid: Cátedra, pp.13-149.

Basualdo, Ana (1986). «Jaime Siles: el instinto del lenguaje (entrevista)», La Vanguardia. Barcelona, 11-II-1986, p. 35.

Bousoño, Carlos (1999). Teoría de la expresión poética. Sexta edición. Madrid: Gredos.

Campbell, Joseph (1999). El héroe de las mil caras. Psicoanálisis del mito. México: FCE.

Castro, Idoli (2009). Jaime Siles: une poésie de la pensé et une pensé poétique. Saint-Étienne: Publications de l'Université de Saint-Étienne.

Chevalier, Jean y Alain Gheerbrant (1999). Diccionario de los símbolos. Sexta edición. Barcelona: Herder.

Debicki, Andrew P. (1997). Historia de la poesía española del siglo XX. Desde la modernidad hasta el presente. Madrid: Gredos.

Falcón, Constantino, Emilio Fernández y Raquel López (eds.) (2001), Diccionario de mitología clásica. V. 1. Madrid: Alianza.

García Jambrina, Luis (7.3.2009). «Fuera del tiempo», ABC Cultural. 2009, pp. 18-19.

Graves, Robert (2005). Los mitos griegos. Barcelona: RBA.

Jiménez, José Olivio (1976). «La palabra esencial y tensa de Jaime Siles: Sobre Canon (1973)», Diálogos. 68 (marzo-abril), pp. 31-33. [También en Litoral (Ejemplar dedicado a: Palabra. Mundo. Ser: la poesía de Jaime Siles), pp. 166-168].

Martín Pardo, Enrique (1970). Nueva poesía española. Madrid: Scorpio.

Mauron, Charles (1962). Des métaphores obséndentes au mythe personnel. Introduction à lo psychocritique. París: Jose Corti.

Morcillo, Françoise (2002). Jaime Siles: un poète espagnol «classique contemporain». Paris: L'Harmattan.

Rueda, Ana (1999). Pigmalión y Galatea: refracciones modernas de un mito. Madrid: Fundamentos.

Siles, Jaime (2007). «El yo es un producto del lenguaje», en Poética y poesía. Jaime Siles. Madrid: Fundación Juan March, pp. 19-38.

Siles, Jaime (2011). Cenotafio. Antología poética (1969-2009). Sergio Arlandis (ed.). Madrid: Cátedra.

Tomás, Facundo e Isabel Justo (eds.) (2005). Pigmalión o el amor por lo creado. Barcelona: Anthropos.

Fecha de recepción: 31 de enero de 2013

Fecha de aceptación: 2 de julio de 2013 